\title{
VERMINOSE EM CAPRINOS E OVINOS MANTIDOS EM PASTAGENS DE Panicum maximum Jacq. NO PERÍODO CHUVOSO DO ANO
}

\author{
Danilo Gusmão de Quadros, ${ }^{1}$ Américo Garcia da Silva Sobrinho, ${ }^{2}$ Luis Roberto de Andrade Rodrigues, ${ }^{2 \dagger}$ \\ Gilson Pereira de Oliveira, ${ }^{3}$ Cláudia Pereira Xavier,${ }^{4}$ Alexandro Pereira Andrade, ${ }^{4}$ Maria Luisa de \\ Carvalho Souza e Cunha e José Valmir Feitosa ${ }^{5}$
}

\author{
1. Professor adjunto da Universidade do Estado da Bahia. E-mail: uneb_neppa@yahoo.com.br \\ 2. Professor adjunto, FCAV/UNESP $-{ }^{\dagger}$ In memoriam \\ 3. Pesquisador do Centro de Pesquisas em Sanidade Animal, UNESP \\ 4. Acadêmicos da Universidade do Estado da Bahia \\ 5. Professor adjunto II da Universidade Federal do Ceará
}

RESUMO

O objetivo deste trabalho foi o de avaliar a verminose em caprinos e ovinos mantidos em pastagens de Panicum maximum Jacq. na época chuvosa do ano. Quantificaram-se a densidade de massa seca (MS) dos diferentes estratos $(0-15,15-$ 30 e acima de $30 \mathrm{~cm}$ ) da pastagem e a contaminação da forragem por larvas infectantes de nematódeos gastrintestinais (L3). Os quarenta animais foram submetidos a exames coprológicos mensais (OPG e coprocultura) no período chuvoso do ano. O experimento foi realizado em Barreiras, BA, sendo delineado em parcelas subdivididas distribuídas ao acaso, com dez repetições na pastagem e vinte nos animais, de outubro de 2003 a março de 2004, ao passo que as amostragens ocorreram nos meses de dezembro a fevereiro. O número total de larvas infectantes $/ \mathrm{kg}$ MS não variou com o estrato, obtendo-se a média de 22,2 L3/ kg MS. Na forragem, identificaram-se larvas L3 de Haemonchus sp. e Trichostrongylus sp., refletindo os resultados das coproculturas. Caprinos apresentaram maior contagem de OPG (2602) do que os ovinos (865), demandando maiores cuidados sanitários.

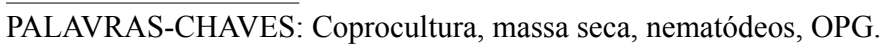

ABSTRACT

WORM DISEASE ON GOATS AND SHEEP RAISED ON Panicum maximum Jacq. PASTURES IN THE RAINY SEASON ${ }^{1}$

The objective of this work was to evaluate the worm disease on goats and sheep kept on Panicum maximum Jacq. pastures, in the rainy season of the year. The dry matter density (DM) of different layers $(0-15,15-30$ and above $30 \mathrm{~cm})$ of Panicum maximum Jacq. pastures, and the forage contamination by gastrintestinal nematode infective larvae (L3) were quantified. Forty animals were submitted monthly to coproparasitological examinations (ECG and coproculture) during the rainy season. The experiment was carried out in Barreiras-Bahia-Brazil, in a split-plot design, with 10 replications on pastures and 20 replications on animals, from October of 2003 to March of 2004, and samples were taken from December to February. The number of infective larvae per $\mathrm{kg} / \mathrm{DM}$ did not change with the grass layer, with average of 22.2 L3/kg DM. On the forage, Haemonchus sp. and Trichostrongylus $s p$. L3 larvae were indentified, reflecting the coproculture results. Goats showed higher ECG counting (2602) than Sheep (865), demanding more sanitary care.

KEYWORDS: Coproculture, dry matter, ECG, nematodes. 


\section{INTRODUÇÃO}

Na região Nordeste, encontram-se $93 \%$ dos caprinos e $58 \%$ dos ovinos do Brasil, tendo o Estado da Bahia cerca de quatro e três milhões de cabeças, respectivamente, sendo o maior rebanho caprino e segundo rebanho ovino do território brasileiro (IBGE, 2006). Apesar da elevada importância socioeconômica da caprinovinocultura, constata-se que a maioria dos criatórios apresenta baixos índices produtivos, devido, entre outros, à alimentação e sanidade.

A forragem produzida na pastagem é a fonte mais barata de alimentos para viabilizar a produção de pequenos ruminantes. Entretanto, nesse ecossistema, a verminose é considerada o principal problema sanitário na criação de caprinos (BOMFIM \& LOPES, 1994) e ovinos (AMARANTE, 2001), sendo que a infecção do hospedeiro ocorre por meio da pastagem contaminada com a forma larval infectante (L3). Dentre os helmintos, considerando-se a distribuição geográfica e os danos econômicos, os nematódeos gastrintestinais são mais significativos.

Gramíneas forrageiras eretas apresentam estruturas que permitem certa penetração de raios solares nas bases das plantas, que poderia reduzir o número de ovos e larvas infectantes pela dessecação (BUENO et al., 2008). Estrutura da pastagem conceitua-se como a disposição horizontal e vertical que a forragem apresenta-se aos animais, sendo variável com o genótipo, idade da planta, época do ano e manejo, além de afetar diretamente o comportamento ingestivo (CARVALHO et al., 2007; PAULA et al., 2009).

No semiárido brasileiro, os caprinos e ovinos geralmente são criados juntos. A associação de diferentes espécies animais em lotação múltipla é prática antiga, cujos objetivos são o controle biológico de plantas indesejáveis, o aproveitamento de áreas topograficamente inacessíveis, a manipulação biológica da vegetação, a oferta de forragem com alto valor nutritivo aos animais em produção, a estabilização da vegetação manipulada (ARAÚJO FILHO \& CRISPIM, 2002), além do controle de nematódeos gastrintestinais (AMARANTE, 2001). A utilização mais intensiva dos recursos pode ser possível considerando as diferenças anatômicas, fisiológicas e comportamentais das espécies envolvidas, utilizando a forragem produzida de maneira complementar (ARAÚJO FILHO \& CRIS-
PIM, 2002). Contudo, em relação às nematodioses, não há benefício direto da associação das espécies caprina e ovina, dada a ocorrência de infecção cruzada (QUADROS \& VIEIRA, 2009). Quando mantidos em pastagens exclusivas de gramíneas, considerando os hábitos alimentares ramoneiador, dos caprinos, e mais pastejador, dos ovinos, as espécies podem comportarse diferentemente em relação ao grau de infecção por nematódeos gastrintestinais (POMROY et al., 1986).

Sendo base do sistema alimentar dos ruminantes, as plantas forrageiras concentram de $80 \%$ a $90 \%$ da produção anual de massa seca (MS) na época quente e chuvosa do ano, considerando a maior parte do território nacional, consequentemente melhor período de utilização. A estacionalidade é marcante em Panicum maximum Jacq., no qual ocorre drástica redução quantitativa e qualitativa da forragem, diminuindo a capacidade de suporte (CORRÊA \& SANTOS, 2003).

Com o presente trabalho objetivou-se avaliar a verminose em caprinos e ovinos mantidos em pastagens de Panicum maximum Jacq. na época chuvosa do ano.

\section{MATERIAL E MÉTODOS}

O experimento foi realizado na Fazenda Cabanha Santo Ângelo, no município de Barreiras (1209'S de latitude, $45^{\circ} 00^{\prime} \mathrm{W}$ de longitude e $439 \mathrm{~m}$ de altitude), na região oeste do Estado da Bahia. Utilizaram-se três piquetes de aproximadamente 1,0 ha de Panicum maximum Jacq., o primeiro do cv. Mombaça, que fora irrigado para suprimento de forragem aos animais da propriedade no período seco do ano, ao passo que o segundo e o terceiro, dos cvs. Tanzânia e Mombaça, respectivamente, eram mais recentes, os quais, um a um, foram submetidos à lotação de quarenta animais - vinte ovinos e vinte caprinos. As amostragens foram realizadas após o tempo mínimo de permanência dos animais nos piquetes de 21 dias. A primeira delas ocorreu no final de dezembro e no início de janeiro. As demais, em fevereiro e março.

A tipologia climática do município de Barreiras é de subúmido a seco, na classificação de Thornthwaite \& Matther, com pequeno excedente hídrico, megatérmico (evapotranspiração $>1.140 \mathrm{~mm}$ ) e com chuvas de primavera/verão. Os dados meteorológicos foram oriundos do Instituto Nacional de Meteorolo- 
gia (INMET). As chuvas praticamente iniciaram-se em novembro, mas intensificaram-se em janeiro e fevereiro (Tabela 1). Comparado à média histórica, $\mathrm{o}$ índice pluviométrico foi baixo nos meses de outubro e novembro, intensificando-se em dezembro, janeiro e março.

TABELA 1. Valores médios de precipitação pluvial, temperaturas máxima, mínima e média, em Barreiras, BA, de outubro de 2003 a março de 2004

\begin{tabular}{|c|c|c|c|c|c|c|c|c|}
\hline \multirow{2}{*}{ Mês } & \multicolumn{2}{|c|}{ Precipitação pluvial (mm) } & \multicolumn{2}{|c|}{ Temperatura média $\left({ }^{\circ} \mathrm{C}\right)$} & \multicolumn{2}{|c|}{ Temperatura máxima $\left({ }^{\circ} \mathrm{C}\right)$} & \multicolumn{2}{|c|}{ Temperatura mínima $\left({ }^{\circ} \mathrm{C}\right)$} \\
\hline & $\begin{array}{c}\text { Ano } \\
2003 / 2004\end{array}$ & $\begin{array}{c}\text { Média } \\
\text { histórica }\end{array}$ & $\begin{array}{c}\text { Ano } \\
2003 / 2004\end{array}$ & $\begin{array}{l}\text { Média } \\
\text { histórica }\end{array}$ & $\begin{array}{c}\text { Ano } \\
2003 / 2004\end{array}$ & $\begin{array}{c}\text { Média } \\
\text { histórica }\end{array}$ & $\begin{array}{c}\text { Ano } \\
2003 / 2004\end{array}$ & $\begin{array}{c}\text { Média } \\
\text { histórica }\end{array}$ \\
\hline Outubro & 34,0 & 84,3 & 28,3 & 27,1 & 35,4 & 34,1 & 21,1 & 20,1 \\
\hline Novembro & 136,4 & 151,7 & 25,7 & 26,2 & 31,7 & 32,1 & 19,7 & 20,3 \\
\hline Dezembro & 118,8 & 171,5 & 27,3 & 25,6 & 33,5 & 31,1 & 21,0 & 20,0 \\
\hline Janeiro & 318,4 & 162,4 & 25,1 & 25,5 & 29,2 & 31,0 & 20,9 & 19,9 \\
\hline Fevereiro & 201,2 & 154,0 & 25,5 & 25,5 & 30,0 & 31,0 & 21,0 & 20,0 \\
\hline Março & 210,4 & 154,1 & 25,3 & 25,5 & 29,8 & 31,0 & 20,8 & 20,0 \\
\hline
\end{tabular}

Fonte: INMET, Barreiras.

Foram utilizadas ovelhas da raça Santa Inês e cabras da raça Anglonubiana e mestiças, fora do período periparto, com massas corporais estimadas em $45 \mathrm{e}$ $50 \mathrm{~kg}$ PV, respectivamente, e idade variando de 1,5 a 3 anos. O propósito da criação desses animais era produção de carne, e o manejo foi semelhante, permanecendo em lotação associada. Durante a noite, eram presos em instalações rústicas e no início da manhã, aproximadamente às $7 \mathrm{~h} 30 \mathrm{~min}$, tiveram acesso ao piquete, dispondo de água e mistura mineral ad libitum.

A MS das frações lâminas foliares verdes (folha), colmos + bainhas (colmo) e material morto dos estratos de 0-15, 15-30 e acima de $30 \mathrm{~cm}$, da parte aérea dos capins, foi determinada pelo corte, separação e secagem da forragem contida em quadrado de $0,5 \mathrm{~m}$ de lado $\left(0,25 \mathrm{~m}^{2}\right)$, em dez touceiras por piquete, seguindo linhas transectas imaginárias. A secagem das amostras, para cálculo do percentual de matéria seca e da MS/estrato ( $\mathrm{kg} / \mathrm{ha})$, foi realizada em estufa com circulação forçada de ar, a $60^{\circ} \mathrm{C}$ por 72 horas (SILVA \& QUEIROZ, 2002).

O percentual de cobertura do solo pelo capim, plantas daninhas e área descoberta foi estimado visualmente por dois observadores, em avaliação não destrutiva, utilizando-se quadrado com $1 \mathrm{~m}$ de lado, em oito pontos por piquete (ANDRADE et al., 2005). Não houve influência do observador ( $p>0,05)$ na avaliação visual da cobertura do solo. Os valores de cobertura do solo pelo capim foram multiplicados pela $\mathrm{MS} / \mathrm{ha}$ de cada estrato, transformando-se os dados conforme o perfil de ocupação do solo.

A altura das plantas foi medida em vinte pontos por piquete, com o auxílio de régua graduada em centímetros. Dividindo-se a MS dos componentes morfológicos de cada estrato pela altura, calculou-se a densidade de folhas, colmos e material morto $(\mathrm{kg}$ $\mathrm{MS} / \mathrm{ha} / \mathrm{cm})$.

Uma subamostra, de aproximadamente $200 \mathrm{~g}$ da forragem de cada estrato, foi utilizada para extração das larvas infectantes, pela técnica adaptada de MARTIN et al. (1990). As amostras do capim foram colhidas de 9 às $10 \mathrm{~h}$ da manhã, levando-as ao Laboratório no câmpus IX-UNEB, situado a $12 \mathrm{~km}$ da Fazenda Experimental, para pesagem e colocação em baldes contendo $10 \mathrm{~L}$ de água por dezoito horas. Em seguida, o capim foi retirado e o líquido remanescente permaneceu decantando por mais seis horas, para ser sifonado até restar aproximadamente $300 \mathrm{~mL}$, o qual foi posto em aparelho de Baermann. Após 24 horas, coletaram-se $15 \mathrm{~mL}$ do decantado em tubo de ensaio e, depois de, no mínimo 24 horas em geladeira, $3 \mathrm{~mL}$ foram pipetados para identificação e contagem das 
larvas infectantes (KEITH, 1953) em câmara de vidro, acrescidos de três gotas de lugol fraco (1\%), utilizando microscópio ótico com aproximação de 10x e 30x. O número de larvas na MS da subamostra foi convertida para $\mathrm{kg}$ de MS.

CASTRO et al. (2003), ao utilizarem a técnica de Baermann em Paspalum notatum Flugge, relataram quantidades consideráveis de sujidades, as quais podem dificultar a identificação e a contagem de larvas infectantes. No presente trabalho, ocorreu esse problema, principalmente nos estratos com grande quantidade de material morto.

Os animais experimentais foram naturalmente infectados por nematódeos gastrintestinais, não sendo submetidos à aplicação de anti-helmíticos desde noventa dias antes do experimento até o final do experimento. As fezes dos animais foram colhidas na mesma ocasião das amostragens no piquete. Para a contagem de OPG, utilizou-se solução saturada de cloreto de sódio $(\mathrm{NaCl})$ e realizou-se leitura no microscópio óptico em câmara McMaster (GORDON \& WHITLOCK, 1939). Parte das amostras de fezes foi utilizada para coprocultura (ROBERT \& O'SULLIVAN, 1950), usando como substrato a serragem úmida ou vermiculita. As larvas foram classificadas pelo gênero (KEITH, 1953).

Realizou-se o experimento segundo delineamento inteiramente casualizado em esquema de parcela subdividida, com dez repetições, para medidas dos efeitos dos estratos $(0-15,15-30$ e acima de $30 \mathrm{~cm})$ sobre a densidade de MS de folhas, colmos e material morto, além da concentração de larvas infectantes de nematódeos gas- trintestinais. Entretanto, utilizaram-se vinte repetições (animal como unidade experimental), quando avaliado o efeito da espécie caprina ou ovina sobre a contagem de OPG e resultados das coproculturas. Foram amostradas três épocas de avaliação, com medidas repetidas no tempo, dentro da época chuvosa do ano, conforme regime pluvial da região dos cerrados baianos.

Os dados obtidos na contagem de OPG e de larvas infectantes $/ \mathrm{kg}$ MS obtidos foram transformados em $\log _{10}$ $(\mathrm{x}+1)$ e submetidos à análise de variância pelo teste F, sendo as médias comparadas pelo teste de Tukey, ao nível de 5\% de probabilidade, utilizando-se o Programa Estatístico ESTAT, da UNESP-Jaboticabal.

\section{RESULTADOS E DISCUSSÃO}

A altura média da gramínea forrageira não atingiu $1 \mathrm{~m}$, evitando-se o fenômeno de rejeição da forragem pelos animais. No manejo de pastagens com pequeno ruminantes, recomendam-se alturas de entrada dos animais nos piquetes quando o capim atingir medidas inferiores à do focinho dos animais, conforme SANTOS et al. (2002). Segundo esses autores, dado o hábito social gregário dos ovinos, quando o capim supera $1 \mathrm{~m}$ há grande rejeição de forragem, pois eles buscam uns aos outros ao redor das cercas, adentrandose relativamente pouco ao interior do piquete.

A altura do capim de 36 a $75 \mathrm{~cm}$, observada neste trabalho, foi semelhante à observada por BRÂNCIO et al. (2003) (35-80 cm), comparando-se os cultivares Tanzânia, Mombaça e Massai de P. maximum sob pastejo de bovinos, em área de cerrados.

TABELA 2. Altura das plantas e cobertura do solo pelo capim, plantas daninhas e solo descoberto, em pastagens de Panicum maximum Jacq. manejadas com ovinos e caprinos, no período chuvoso do ano

\begin{tabular}{|c|c|c|c|c|}
\hline \multirow{2}{*}{ Mês de amostragem } & \multirow{2}{*}{ Altura das plantas $(\mathrm{cm})$} & \multicolumn{3}{|c|}{ Cobertura do solo (\%) } \\
\hline & & Capim & Plantas daninhas & Solo descoberto \\
\hline Dez & $49,0 \mathrm{~B}$ & $57,6 \mathrm{AB}$ & $2,6 \mathrm{~B}$ & $39,5 \mathrm{~A}$ \\
\hline Jan & $36,4 \mathrm{C}$ & $53,5 \mathrm{~B}$ & $24,8 \mathrm{~A}$ & $21,7 \mathrm{~B}$ \\
\hline $\mathrm{Fev}$ & $75,2 \mathrm{~A}$ & $71,2 \mathrm{~A}$ & $3,12 \mathrm{~B}$ & $25,2 \mathrm{~B}$ \\
\hline Desvio-padrão & 22,3 & 9,3 & 12,7 & 9,4 \\
\hline
\end{tabular}

Médias na mesma coluna seguidas de letras diferentes são distintas, pelo teste de Tukey a $5 \%$. 
A cobertura do solo por gramíneas forrageiras, situada entre $57,6 \%$ e $71,2 \%$ (Tabela 2 ), foi considerada satisfatória, quando comparada aos 52\%-60\%, observados por ANDRADE et al. (2005), em avaliação dos capim-tanzânia, estrela-africana e andropógon sob pastejo ovino.

A densidade de folhas foi menor no estrato basal em relação aos superiores (Tabela 3), semelhante ao observado por HOLDERBAUN \& SOLLENBERG
(1992) nas metades basal $(25 \mathrm{~kg} / \mathrm{ha} / \mathrm{cm})$ e superior $(36$ $\mathrm{kg} / \mathrm{ha} / \mathrm{cm}$ ) do capim-hemártria (Hemarthria altissima (Poir.) Stapf \& Hubbard). A variação de 10,4 a 84,8 kg/ $\mathrm{ha} / \mathrm{cm}$, dos diferentes estratos, encontrada no presente trabalho, foi próxima dos 30 a $100 \mathrm{~kg} / \mathrm{ha} / \mathrm{cm}$ relatada por SOLLEMBERGER \& BURNS (2001) para gramíneas forrageiras tropicais e de 7 a $221 \mathrm{~kg} / \mathrm{ha} / \mathrm{cm}$ observada por RÊGO et al. (2001) em capim-tanzânia manejado com diferentes alturas por bovinos.

TABELA 3. Densidade de folhas, colmos e matéria morta em pastagens de Panicum maximum Jacq. manejadas com ovinos e caprinos, na época chuvosa do ano

\begin{tabular}{|c|c|c|c|c|}
\hline Extrato da pastagem $(\mathrm{cm})$ & Dez. & Jan. & Fev. & Média \\
\hline & \multicolumn{4}{|c|}{ Densidade de folhas $(\mathrm{kg} / \mathrm{ha} / \mathrm{cm})$} \\
\hline $0-15$ & & & & $10,4 \mathrm{~B}$ \\
\hline $15-30$ & & & & $84,6 \mathrm{~A}$ \\
\hline$>30$ & & & & $84,8 \mathrm{~A}$ \\
\hline Média & $28,1 \mathrm{~b}$ & $101,3 \mathrm{a}$ & $50,4 \mathrm{ab}$ & \\
\hline Desvio-padrão & 19,1 & 60,4 & 66,2 & \\
\hline $\mathrm{CV}$ estrato $(\%)$ & 178,0 & & & \\
\hline \multirow[t]{2}{*}{$\mathrm{CV}$ piquete $(\%)$} & 182,0 & & & \\
\hline & \multicolumn{4}{|c|}{ Densidade de colmos (kg/ha/cm) } \\
\hline $0-15$ & $116,6 \mathrm{~A} \mathrm{a}$ & $77,8 \mathrm{~A}$ ab & $25,3 \mathrm{~A} \mathrm{~b}$ & \\
\hline $15-30$ & $15,3 \mathrm{~B} \mathrm{a}$ & $55,4 \mathrm{~A} \mathrm{a}$ & $96,1 \mathrm{~A} \mathrm{a}$ & \\
\hline$>30$ & $0,2 \mathrm{~B}$ a & $43,3 \mathrm{~A} \mathrm{a}$ & $12,0 \mathrm{~A} \mathrm{a}$ & \\
\hline Desvio-padrão & 135,4 & 39,1 & 32,6 & \\
\hline CV estrato $(\%)$ & 183,0 & & & \\
\hline \multirow[t]{2}{*}{ CV época de amostragem ( $\%)$} & 172,0 & & & \\
\hline & \multicolumn{4}{|c|}{ Densidade de matéria morta $(\mathrm{kg} / \mathrm{ha} / \mathrm{cm})$} \\
\hline $0-15$ & $226,7 \mathrm{~A}$ a & $208,1 \mathrm{~A} \mathrm{a}$ & $17,3 \mathrm{~A} \mathrm{~b}$ & \\
\hline $15-30$ & $101,6 \mathrm{~B}$ a & $72,6 \mathrm{~B}$ a & $28,0 \mathrm{~A} \mathrm{a}$ & \\
\hline$>30$ & $35,2 \mathrm{C} \mathrm{a}$ & $15,6 \mathrm{~B} \mathrm{a}$ & $10,2 \mathrm{~A} \mathrm{a}$ & \\
\hline Desvio-padrão & 143,1 & 89,9 & 20,1 & \\
\hline CV estrato $(\%)$ & 93,5 & & & \\
\hline CV época de amostragem (\%) & 92,5 & & & \\
\hline
\end{tabular}

Dentro de cada fator e dentro de cada variável, médias seguidas de pelo menos uma mesma letra, maiúsculas na mesma coluna e minúsculas na linha, não são significativamente diferentes (Teste de Tukey, $5 \%$ ).

$\mathrm{CV}=$ Coeficiente de variação.

Foi evidenciada alta densidade de colmos no estrato abaixo da altura de resíduo pós-pastejo para cultivares de maior porte de P. maximum, como Tanzânia e Mombaça (Tabela 3). HOLDERBAUM et al. (1992) observaram maiores densidades de colmos na metade inferior do capim-hemártria em relação ao topo, sendo de 222 e $74 \mathrm{~kg} / \mathrm{ha} / \mathrm{cm}$, respectivamente. Altas densidades de colmos podem ocasionar alterações na ingestão e redução da qualidade da dieta. Dificuldades de manejo de gramíneas forrageiras tropicais são re- 
conhecidas, em virtude, entre outros, da alta variação sazonal de crescimento, do alongamento e formação dos colmos (DA SILVA \& NASCIMENTO JÚNIOR, 2007).

A densidade de material morto concentra-se nos estratos inferiores (Tabela 3), tendo relação com o percentual de utilização da forragem produzida. O sombreamento na base das plantas, intra ou interespecífica, pode acelerar a morte dos tecidos e, considerando na morfogênese o crescimento acropetalar dos perfilhos, as folhas baixeiras senescem primeiro, pois têm idade fisiológica mais avançada (DA SILVA \& NASCIMENTO JÚNIOR, 2007). A estrutura da pastagem e a proporção de forragem verde, em oposição à morta, são os dois fatores de maior influência na seleção da dieta pelos herbívoros, apesar da importância de fatores sensoriais (gosto, odor e textura) (FAGUNDES et al., 1999).

A grande variação na estrutura da pastagem, observada no presente trabalho, corrobora a de SOLLEMBERGER \& BURNS (2001), que verificaram alto grau de heterogeneidade na distribuição horizontal e vertical em pastagens tropicais, tanto em termos quantitativos quanto qualitativos.

$\mathrm{Na}$ pastagem foram identificadas larvas infectantes de nematódeos gastrintestinais dos gêneros Haemonchus sp. e Trichostrongylus sp. (Figura 1), semelhante ao observado por AMARANTE \& BARBOSA (1998), em capim-coast-cross (Cynodon dactilon (L.) Pers.) sob lotação ovina na região de Botucatu, Estado de São Paulo.

O número de larvas infectantes de Haemonchus sp. + Trichostrongylus sp. (total) não variou estatisticamente com o $(\mathrm{P}>0,05)$ com o estrato do capim (Figura 1a), com média de 22,2 L3/kg MS, valor semelhante ao observado por MACEDO et al. (2002), em pastagem de capimtanzânia, manejada com ovinos, no oeste do Paraná. O produto da média do número de larvas/kg MS e MS/ha do capim resultou em 577 mil larvas/ha, indicativo da contaminação do pasto e das boas condições ambientais da eclosão e desenvolvimento das larvas. MISRA \& RUPRAH (1972) observaram migrações de larvas de $H$. contortus a alturas, em geral, de 12,5 a $15 \mathrm{~cm}$, podendo atingir de 17,5 a 22,5 cm nos dias mais chuvosos.

Não houve efeito significativo do estrato sobre o número de larvas infectantes de Trichostrongylus sp., com média de 9,7 L3/kg MS (Figura 1a). Entretanto, o de Haemonchus spp. foi afetado pela interação entre es- trato e mês da amostragem (Figura 1b). Em dezembro, a forragem estava bem mais contaminada $(\mathrm{P}<0,05)$ no estrato basal, em comparação aos meses subsequentes. Possivelmente, a irrigação e permanência de alguns animais na época seca no pasto tenham influenciado o grau contaminação.

A contagem de OPG foi maior $(\mathrm{P}<0,05)$ nos caprinos (2602) do que nos ovinos (865). Entretanto, deve-se observar que se utilizaram ovinos de uma raça resistente, em relação aos caprinos, de uma raça susceptível. Portanto, não é possível generalizar estes resultados.

a)

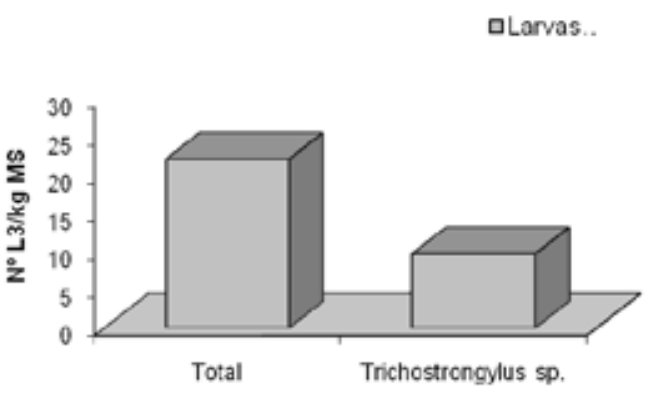

b)

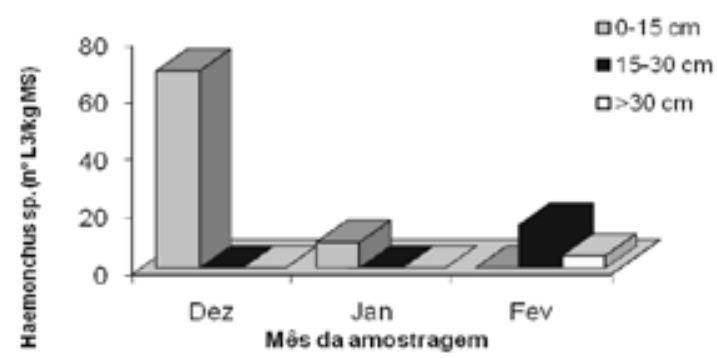

FIGURA 1. Concentração de larvas infectantes de Trichostrongylus sp. (a) e de Haemonchus sp. (b) em pastagens de P. maximum manejadas com caprinos e ovinos, na época chuvosa.

Em se tratando de infecções mistas, a contagem de OPG na faixa de 50-800 é classificada como uma infecção de grau leve, de 800-1200, moderado, e acima de 1.200, pesado. Em relação à ação exclusiva do gênero Haemonchus sp., esse valores são de 100-2000, 2000-7000 e > 7000; e Trichostrongylus sp., de 100500, 500-2000 e > 2000, para leve, moderado e pesado, respectivamente (HANSEN \& PERRY, 1994).

A influência do comportamento alimentar sobre o número de larvas infectantes ingerido é hipótese para 
explicar as diferenças na intensidade de infecção por nematódeos entre espécies, ou raças (HOSTE et al., 2001). Caprinos mantidos em pastagens exclusivas de gramíneas foram mais infectados por nematódeos do que ovinos (POMROY et al., 1986). No entanto, efeito inverso foi observado quando tiveram a possibilidade do ramoneio, em vegetação botânica heterogênea (VERCRUYSSE, 1983).

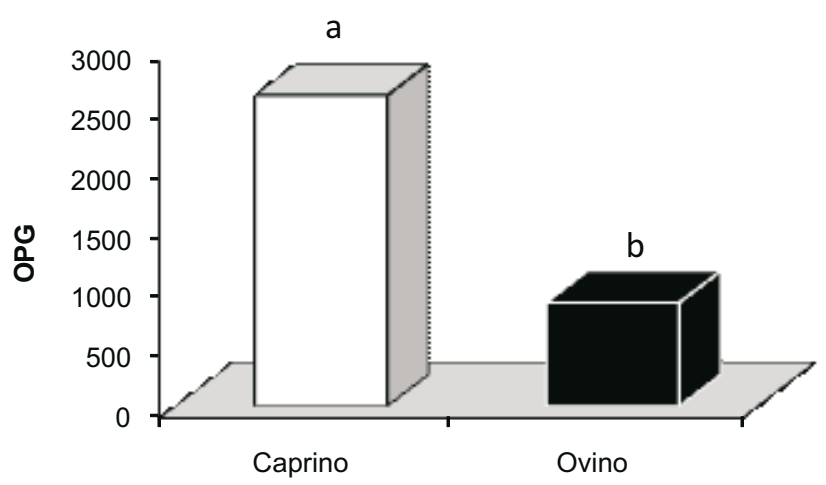

FIGURA 2. Contagem de ovos por grama de fezes (OPG) em caprinos e ovinos mantidos em pastagens de Panicum maximum Jacq. na época chuvosa do ano.

*Letras diferentes indicam diferença significativa, pelo teste de Tukey $(\mathrm{P}<0,05)$.

Tanto caprinos quanto ovinos apresentaram nas coproculturas maior prevalência (44-94\%) de nematódeos do gênero Haemonchus sp., com crescimento acentuado da participação de Trichostrongylus sp. no final das "águas" (Figura 3). Sendo reconhecidamente o $H$. contortus um nematódeo de alta prevalência na criação de caprinos (BOMFIM \& LOPES, 1994) e ovinos (AMARANTE, 2001), o transporte de animais que vem ocorrendo acentuadamente do Nordeste para início de plantel em outras regiões brasileiras pode levar à disseminação do parasito, se as condições ambientais forem adequadas ao seu desenvolvimento.

As prevalências dos nematódeos gastrintestinais obtidas neste trabalho foram semelhantes às relatadas por AMARANTE et al. (1996), referentes aos ovinos em lotação associada aos bovinos, bem como por MARTIN NIETO et al. (2003), relativos aos ovinos mantidos em pastagens com capins de hábitos de crescimento distintos, e BORGES (2003), em marrãs caprinas leiteiras, sob criação semi-intensiva. a) Caprinos

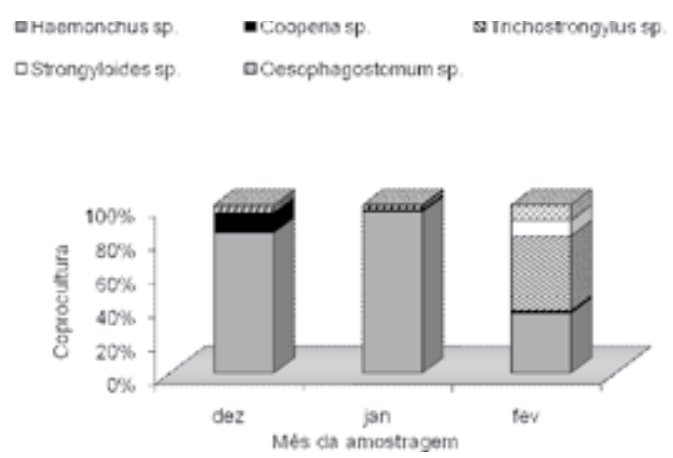

b) Ovinos

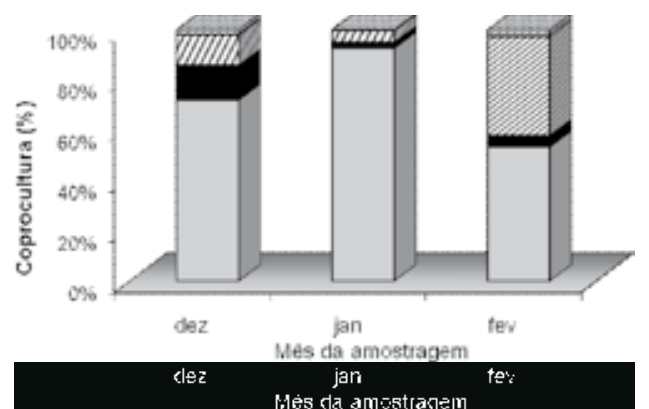

FIGURA 3. Resultados das coproculturas de caprinos (a) e ovinos (b) mantidos em pastagens de Panicum maximum Jacq., no período chuvoso do ano.

\section{CONCLUSÕES}

Foram identificadas, na forragem, larvas infectantes de Haemonchus sp. e Trichostrongylus sp. em densidades variáveis nos diferentes estratos da pastagem. Nesse contexto, ovinos e caprinos pastejando associadamente apresentaram graus infecção moderado e alto, respectivamente, com notáveis prevalências de Haemonchus sp., Trichostrongylus sp.

\section{AGRADECIMENTOS}

Ao professor Alvimar José da Costa, extensivos à equipe do Centro de Pesquisa em Parasitologia (CPPAR) da Faculdade de Ciências Agrárias e Veterinárias, Universidade Estadual Paulista (FCAVUNESP), câmpus de Jaboticabal, pelo treinamento das metodologias fundamentais à realização deste trabalho. 


\section{REFERÊNCIAS}

AMARANTE, A. F. T. Controle de endoparasitoses em ovinos. In: REUNIÃO ANUAL DA SOCIEDADE BRASILEIRA DE ZOOTECNIA, 40., Piracicaba. Anais... Piracicaba:FEALQ/SBZ, 2001. p. 461-473. Disponível em: <http://www.fmvz.unesp.br/ Informativos/ovinos/repman4.htm> Acesso em: 3 out. 2010.

AMARANTE, A. F. T.; BARBOSA, M. A. Comparison between pasture sampling and tracer lambs to evaluate contamination of sheep pastures by nematode infective larvae. Revista Brasileira de Parasitologia Veterinária, v. 7, n. 2, p. 95-99, 1998.

AMARANTE, A. F. T.; PADOVANI, C. R.; BARBOSA, M. A. Contaminação da pastagem por larvas infectantes de nematódeos gastrintestinais parasitas de bovinos e ovinos em Botucatu-SP. Revista Brasileira de Parasitologia Veterinária, v. 5 , n. 2, p. 65-73, 1996.

ANDRADE, A. P.; QUADROS, D. G.; SILVA SOBRINHO, A. G.; RODRIGUES, L. R. A.; SILVA, R. S. Altura das plantas e cobertura do solo em pastagens dos capins estrela-africana, Tanzânia e andropógon manejadas com ovinos. In: REUNIÃO ANUAL DA SOCIEDADE BRASILEIRA DE ZOOTECNIA, 52., 2005, Goiânia. Anais... Goiania: SBZ, 2005. Disponível em: <http://www. neppa.uneb.br/textos/publicacoes/resumos/expandidos/sbz_2005/ pastagem_ovino_altura.htm>. Acesso em: 3 out. 2010.

ARAÚJO FILHO, J. A; CRISPIM, S. M. A. Pastoreio combinado de bovinos, caprinos e ovinos em áreas de caatinga no nordeste do Brasil. In: CONFERÊNCIA VIRTUAL GLOBAL SOBRE PRODUÇÃO ORGÂNICA DE BOVINOS DE CORTE, 2002. 7 p. Disponível em: $<$ http://www.cpap.embrapa.br/agencia/congressovirtual/pdf/portugues/03pt08.pdf $>$. Acesso em: 3 out. 2010.

BOMFIM, T. C. B.; LOPES, C. W. G. Levantamento de parasitos gastrintestinais em caprinos da região serrana do Estado do Rio de Janeiro. Revista Brasileira de Parasitologia Veterinária, v. 3, n. 2, p. 119-124, 1994.

BORGES, C. C. L. Atividade in vitro de anti-helmínticos sobre as larvas infectantes de namatódeos gastrintestinais de caprinos, utilizando a técnica de coprocultura quantitativa (UENO, 1995). Parasitologia Latinoamericana, v. 58, n. 3-4, p. 142-147, 2003.

BRÂNCIO, P. A.; EUCLIDES, V. P. B.; NASCIMENTO JÚNIOR, D.; FONSECA, D. M.; ALMEIDA, R. G.; MACEDO, M. C. M.; BARBOSA, R. A. Avaliação de três cultivares de Panicum maximum Jacq. sob pastejo: disponibilidade de forragem, altura de resíduo pós-pastejo e participação de folhas, colmos e material morto. Revista Brasileira de Zootecnia, v. 32, n. 1, p. 55-63, 2003.

BUENO, M. S.; VERÍSSEMO, C. J.; CUNHA, E. A.; SANTOS, L. E. O controle da verminose em sistema intensivo de produção de ovinos para abate. In: VERÍSSEMO, C. J. (Cord.). Alternativas de controle da verminose em pequenos ruminantes. Nova Odessa:Instituto de Zootecnia. 2008. p. 35-50. Disponível em: < http://www.iz.sp.gov.br/pdfs/1249593677.pdf>. Acesso em: 4 out. 2010.

CARVALHO, P. C. F.; KOZLOSKI, G. V.; RIBEIRO FILHO, H. M. N.; REFFATTI, M. V.; GENRO, T. C. M.; EUCLIDES, V. P. B. Avanços metodológicos na determinação do consumo de ruminantes em pastejo. Revista Brasileira de Zootecnia, v. 36, p. 151-170, 2007 (suplemento especial). [online]. Disponível em: $<$ http://www. scielo.br/pdf/rbz/v36s0/16.pdf>. Acesso em: 3 out. 2010.

CASTRO, A. A.; ALMEIDA, L. R.; SILVA, F. J. M.; GUEDES JÚNIOR, D. S.; OLIVEIRA, C. J. F.; ORNELAS, E. I.; FONSECA, A. H. Comparação entre as técnicas de Baermann modificada e Donald utilizadas para recuperar larvas infectantes de nematóides gastrintestinais de ruminantes da pastagem. Revista Brasileira de Parasitologia Veterinária, v. 12. n. 2, p. 88-91, 2003.

CORRÊA, L. A.; SANTOS, P. M. Criação de bovinos de corte na região Sudeste. Embrapa Pecuária Sudeste. Sistemas de Produção, 2. Versão Eletrônica.Jul/2003. Disponível em: $<$ http://sistemasdeproducao.cnptia.embrapa.br/FontesHTML/BovinoCorte/BovinoCorteRegiaoSudeste/mercados.htm>. Acesso: 28 ago. 2006.

DA SILVA, S. C.; NASCIMENTO JÚNIOR, D. Avanços na pesquisa com plantas forrageiras tropicais em pastagens: características morfofisiológicas e manejo do pastejo. Revista Brasileira de Zootecnia, v. 36, p. 122-138, 2007 (suplemento). [online]. Disponível em: $<$ http:// www.scielo.br/pdf/rbz/v36s0/14.pdf >. Acesso em: 3 out. 2010.

FAGUNDES, J. L.; DA SILVA, S. C.; PEDREIRA, C. G. S.; CARNEVALLI, R. A.; CARVALHO, C. A. B.; SBRISSIA, A. F.; PINTO, L. F. M. Intensidades de pastejo e a composição morfológica de pastos de Cynodon spp. Scientia Agricola, v. 56, n. 4, 1999. [online]. Disponível em: $<$ http://www.scielo.br/scielo.php?script=sci_arttext\&pid=S010390161999000400017>. Acesso em: 3 out. 2010.

GORDON, H. McL.; WHITLOCK, H. V. A new technique for counting nematode eggs in sheep faeces. Journal of the Council for Scientific and Industry Research, v. 12, n. 1, p. 50-52, 1939.

HANSEN, J.; PERRY, B. The epidemiology, diagnosis and control of helminth parasites of ruminants, Nairobe: ILRAD-FAO, 1994. Disponível em: <http://www.ilri.cgiar.org/Infoserv/Webpub/ Fulldocs/X5492e00.htm>. Acesso em: 12 jun. 2004.

HOLDERBAUN, J. F.; SOLLENBERG, K. H. Canopy structure and nutritive value of limpograss pastures during mid-summer to early autumn. Agronomy Journal, v. 84, p. 11-16, 1992.

HOSTE, H.; LEVEQUE, H.; DORCHIES P. Comparison of nematode infections of the gastrointestinal tract in Angora and dairy go- 
ats in rangeland environment: relations with the feeding behaviour. Veterinary Parasitology, v. 101, n. 1-2, p. 127-135, 2001.

IBGE - Instituto Brasileiro de Geografia e Estatística. 2006. Disponível em: $<$ http://www.sidra.ibge.gov.br/bda/tabela/listabl. asp? $=73 \& z=t \& o=20>$. Acesso em: 28 ago. 2006 .

KEITH, R. K. The differentiation of the infective larvae of some commum nematode parasite of cattle. Australian Journal of Zoology, v. 1, n. 2, p. 223-235, 1953.

MACEDO, F. A. F.; MELO, E. P.; MARTINS, E. N.; ZUNDT, M.; MARTIM NIETO, L.; YAMAMOTO, S. M.; MEXIA, A. A.; MACEDO, R. M. G. Infecção de ovelhas por helmintos parasitos e contaminação de pastagens de diferentes hábitos de crescimento. In: REUNIÃO ANUAL DA SOCIEDADE BRASILEIRA DE ZOOTECNIA, 39., 2002, Recife. Anais... Recife, 2002. Resumo. (CD-ROM). Disponível em: <http://www.sbz.org.br/7_reuniaoanual/anais $>$. Acesso em: 3 out. 2010.

MARTIN, R. R.; BEVERIDGE, I.; PULLMAN, A. L.; BROWN, T. H. A modified technique for the estimation of the number of infective nematode larvae present on pasture, and its application in the field under South Australian conditions. Veterinary Parasitology, v. 37, n. 1, p. 133-143, 1990.

MARTIN NIETO, L.; MARTINS, E. N.; MACEDO, F. A. F.; ZUNDT, M. Observações epidemiológicas de helmintos gastrintestinais em ovelhas mestiças manejadas em pastagens com diferentes hábitos de crescimento. Ciência Animal Brasileira, v. 4, n. 1, p. 45-51, 2003.

MISRA, S. C.; RUPRAH, N. S. Vertical migration of Haemonchus contortus infective larvae on experimental grass-plots. Indian Journal of Animal Science, v. 42, n. 10, p. 843-846, 1972.

PAULA, E. F. E.; STUPAK, E. C.; ZANATTA, C. P.; PONCHEKI, J. K.; LEAL, P. C.; MONTEIRO, A. L. G. Comportamento ingestivo de ovinos em pastagens: uma revisão. Revista Tropica - Ciências Agrárias e Biológicas, Chapadinha, v. 4, n. 1, p. 42-51, 2009.

POMROY, W.E.; LAMBERT, M.G.; BETTERIDGE, K. Comparison of faecal strogylate egg counts of goats and sheep on the same pasture. New Zealand Veterinarian Journal, v. 34, n. 1, p. $36-37,1986$.

QUADROS, D. G.; VIEIRA, G. A. Manejo de ovinos e caprinos de corte. In: EXPOBARREIRAS 2009, 27., Barreiras. Anais... Barreiras: Pref. Municipal de Barreiras. 2009. p. 6-29. Disponível em: $<$ http://barreiras.hpdesign.com.br/arquivos/programacao-expo/ anais-textos-das-palestras.pdf $>$. Acesso em: 3 out. 2010.

RÊGO, F. C. A.; CECATO, U.; CANTO, M. C. Densidade e qualidade dos estratos de forragem do capim Tanzânia (Panicum maximum Jacq.) manejado em diferentes alturas, sob pastejo. Acta Scientiarum, v. 23, n. 4, p. 801-807, 2001.

ROBERT, F. H. S.; O’SULLIVAN, P. J. Methods for egg counts and larvae cultures for strongyles infecting. Australian Journal of Agricultural Research, v. 1, n. 1, p. 99-102, 1950.

SILVA, D. J.; QUEIROZ, A. C. Análise de alimentos: métodos químicos e biológicos. 3. ed. Viçosa: UFV, 2002. 235 p.

SILVA, W. W.; BEVILAQUA, C. M. L.; RODRIGUES, M. L. A.Variação sazonal de nematóides gastrintestinais em caprinos traçadores no semi-árido Paraibano - Brasil. Revista Brasileira de Parasitologia Veterinária, v. 12, n. 2, p. 71-75, 2003.

SOLLEMBERGER, L. E.; BURNS, J. C. Canopy characteristics, ingestive behaviour and herbage intake in cultivated tropical pastures. In: INTERNATIONAL GRASSLAND CONGRESS, 19., 2001, São Pedro. Proceedings... Piracicaba:FEALQ, 2001. p. 321-327. Disponível em: <www.internationalgrasslands.org/ publications/pdfs/tema8_2.pdf>. Acesso em: 4 out. 2010.

VATTA, A. F.; KRECEK, R. C.; LETTY, B. A.; van der LINDE, M. J.; MOTSWATSWE, P. W.; HANSEN, J. W. Effect of nematode burden as assessed by means of faecal egg counts on body condition in goats farmed under resource-poor conditions in South Africa. Veterinary Parasitology, v. 108, n. 1-2, p. 247-254, 2002.

VERCRUYSSE, J. A survey of seasonal changes in nematode faecal egg count level of sheep and goats in Senegal. Veterinarian Parasitology, v. 13, n. 1-2, p. 239-244, 1983. 